[Chem. Pharm. Bull.

36(11)4377-4388(1988)

\title{
Studies on 2(1H)-Quinolinone Derivatives as Neuroleptic Agents. I. Synthesis and Biological Activities of (4-Phenyl-1-piperazinyl)- propoxy-2(1H)-quinolinone Derivatives
}

\author{
Kazuo Banno, Takafumi Fujioka, Tetsuro Kikuchi, Yasuo Oshiro, ${ }^{*}$ \\ TAKASHI HiYama and KaZUYUKi NaKagawa \\ Tokushima Research Institute, Otsuka Pharmaceutical Co., Ltd., \\ Kagasuno 463-10, Kawauchi-cho, Tokushima 771-01, Japan
}

(Received February 18, 1988)

\begin{abstract}
With the aim of developing a novel neuroleptic drug, a series of $\omega$-(4-phenyl-1-piperazinyl)alkoxy-2(1H)-quinolinone derivatives have been synthesized and tested for anti-methamphetamine and anti-epinephrine activities. Most of the derivatives were found to possess a potent antimethamphetamine activity in the jumping behavior test on mice treated with 3-(3,4dihydroxyphenyl)-L-alanine (L-DOPA) and methamphetamine, or in the lethality test with methamphetamine-treated mice. They also showed relatively high anti-epinephrine potency depending on the nature or number of substituents on the phenyl group in the 4-phenyl-1piperazinyl moiety; some of these compounds induced only weak catalepsy in mice. Among them, 7-\{3-[4-(2,3-dimethylphenyl)-1-piperazinyl]propoxy\}-2(1H)-quinolinone (OPC-4392), which was suggested to be a dopamine autoreceptor agonist, was selected for further investigations. The structure-activity relationships are also discussed.
\end{abstract}

Keywords-neuroleptic drug; 4-phenyl-1-piperazinylalkoxy; 2(1 H)-quinolinone; antimethamphetamine; anti-epinephrine; jumping behavior; catalepsy; dopamine; autoreceptor; structure-activity relationships

Although central dopamine (DA) receptor blockers are effectively used in the treatment of symptoms of schizophrenia, their use frequently leads to the development of serious extrapyramidal side effects. Furthermore, phenothiazine neuroleptics such as chlorpromazine possess unwanted autonomic side effects associated with their $\alpha$-adrenoceptor blocking activity. Therefore, it is desirable to find drugs which would retain a great efficacy but have minimal undesirable side effects. ${ }^{1-4)}$

We have been investigating the $2(1 H)$-quinolinone derivatives, and we have succeeded in developing some clinically useful drugs. ${ }^{5-7)}$ In the course of the development of the 2(1H)-quinolinone derivatives as anti-histamine agents without central nervous side effects, we found that 7-(4-phenyl-1-piperazinyl)propoxy-3,4-dihydro-2(1H)-quinolinone (Vc-1) had neuroleptic-like activity, causing an increase in the potency of halothane anesthesia in rats. ${ }^{8)}$ We also found that the compound inhibited the stereotypic behavior induced by methamphetamine in rats, but not that by apomorphine. ${ }^{9)}$ In addition, the compound did not exert extrapyramidal side effects such as induction of catalepsy in rats. We synthesized a series of $\omega$ (4-phenyl-1-piperazinyl)alkoxy-2(1H)-quinolinone derivatives in order to find a novel type of neuroleptic with fewer side effects. We describe in this paper the synthesis and preliminary pharmacological examination of the $\omega$-(4-phenyl-1-piperazinyl)alkoxy-2(1H)-quinolinone derivatives.

\section{Synthesis}

The $\omega$-(4-phenyl-1-piperazinyl)alkoxy-2(1H)-quinolinone derivatives (Va-1-VIc-4) listed in Table II were prepared from the corresponding hydroxy-2- $(1 H)$-quinolinone derivatives 


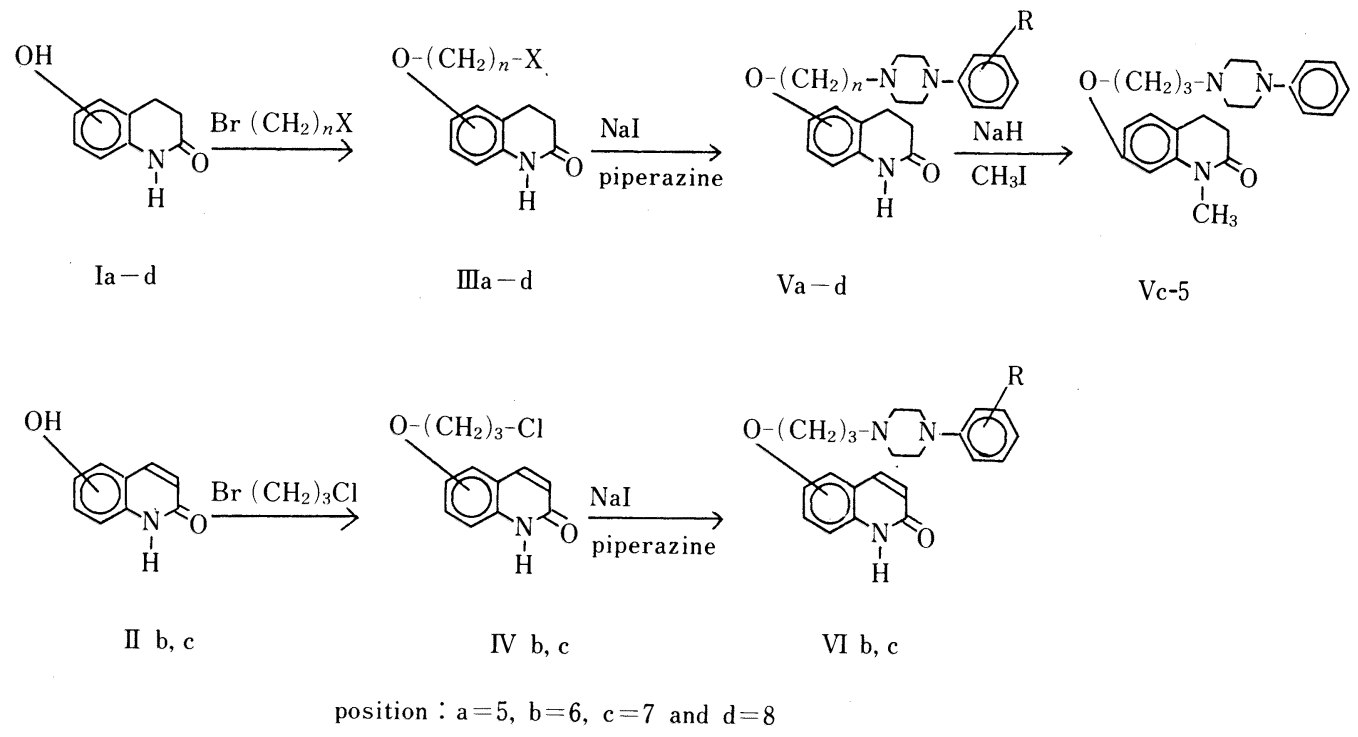

Chart 1

as shown in Chart 1.

The 5,7-and 8-( $\omega$-haloalkoxy)-3,4-dihydro-2-( $1 H$ )-quinolinone derivatives (IIIa-1-IIId) were prepared in a manner similar to that reported for the preparation of the 6- $(\omega-$ haloalkoxy)-3,4-dihydro-2(1H)-quinolinones. ${ }^{7)}$ Treatment of Ia with 1-bromo-3-chloro-propane in the presence of $\mathrm{KOH}$ in iso- $\mathrm{PrOH}$ at reflux temperature gave 5-(3-chloropropoxy)3,4-dihydro-2( $1 H$ )-quinolinone (IIIa-1) in 79\% yield. 7-(3-Chloropropoxy)-2(1H)quinolinone (IVc) was obtained in 39\% yield from IIc (Table I and Experimental section).

Condensation of the $\omega$-haloalkoxy-3,4-dihydro-2( $1 H)$-quinolinones (IIIa-d) with an excess of the 4-phenyl-1-piperazine derivatives in the presence of $\mathrm{NaI}$ in $\mathrm{CH}_{3} \mathrm{CN}$ at reflux temperature gave the corresponding $\omega$-(4-phenyl-1-piperazinyl)alkoxy-3,4-dihydro-2(1H)quinolinone derivatives $(\mathrm{Va}-\mathrm{d})$. Similarly, the 6- or 7-[3-(4-phenyl-1-piperazinyl)propoxy]-2$(1 \mathrm{H})$-quinolinone derivatives (VIb and VIc) were obtained from the corresponding 3chloropropoxy-2(1H)-quinolinones (IVb and IVc). N-Methylation of Vc-1 with methyl iodide and sodium hydride gave the $\mathrm{N}$-methyl derivative (Vc-5).

\section{Pharmacology}

Typical neuroleptic drugs which possess potent DA receptor blocking activity also produce extrapyramidal side effects. For the purpose of the development of a novel neuroleptic drug with less extrapyramidal side effects, we wished to synthesize novel compounds that would exhibit weak or no DA receptor blocking activity but that would depress the release of DA from the presynaptic DA neuron or inhibit synthesis of DA at the DA neuron. As a primary screening method for finding compounds with such properties, we used the anti-jumping behavior test, in which the jumping behavior of mice was produced by injection of DA precursor 3-(3,4-dihydroxyphenyl)-L-alanine (L-DOPA) and DA releaser methamphentamine. ${ }^{10)}$ The neuroleptic activity of the compounds which exhibited relatively high potency in the anti-jumping behavior test was confirmed by measuring their ability to inhibit the lethal effects of methamphetamine on mice. ${ }^{11)}$ Also, their extrapyramidal side effects were examined by measuring the induction of catalepsy in mice. Furthermore, the $\alpha$-adrenoceptor blocking activity of a series of $2(1 H)$-quinolinone derivatives was measured in terms of the ability to provide protection against a lethal dose of epinephrine on mice. These results are 


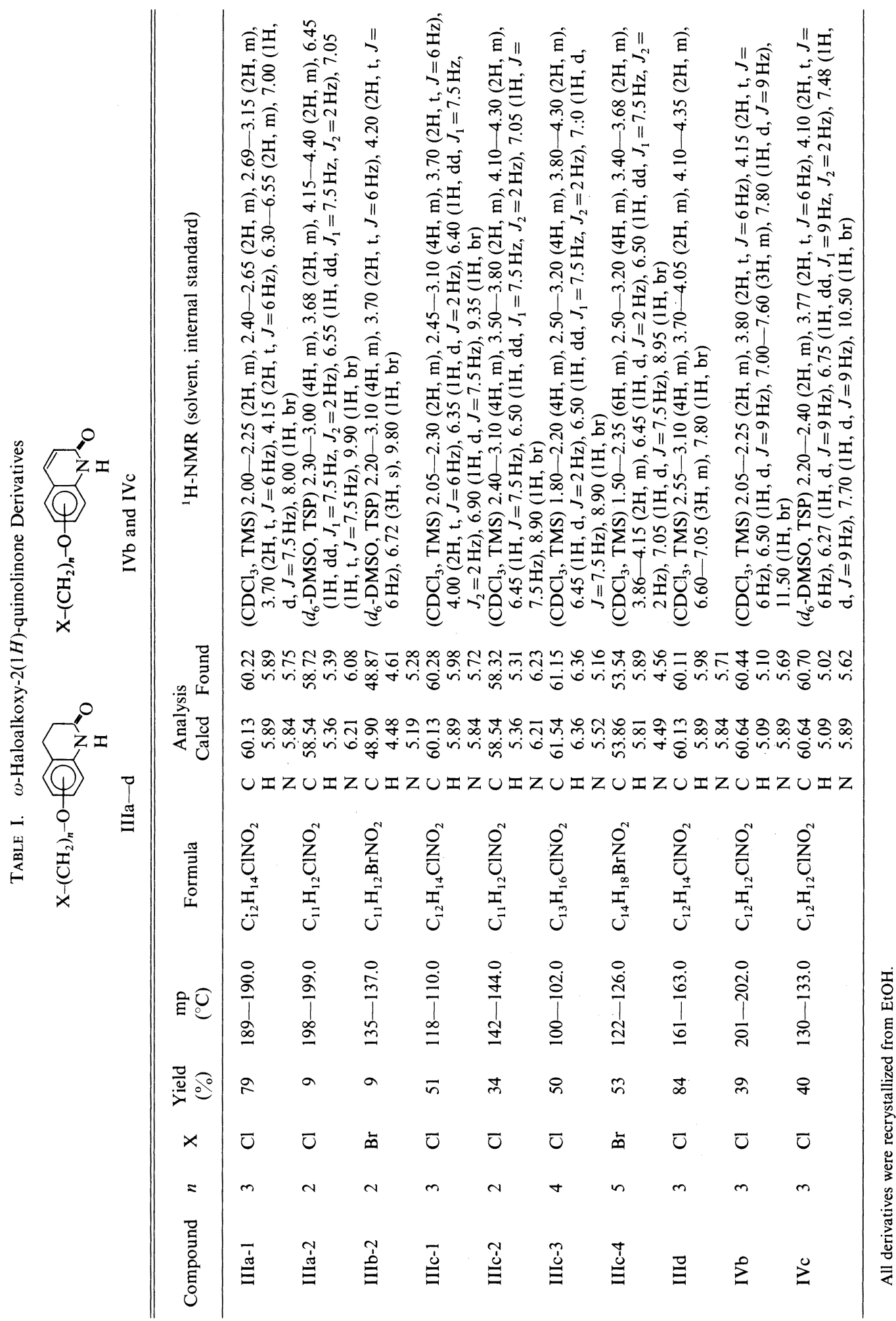




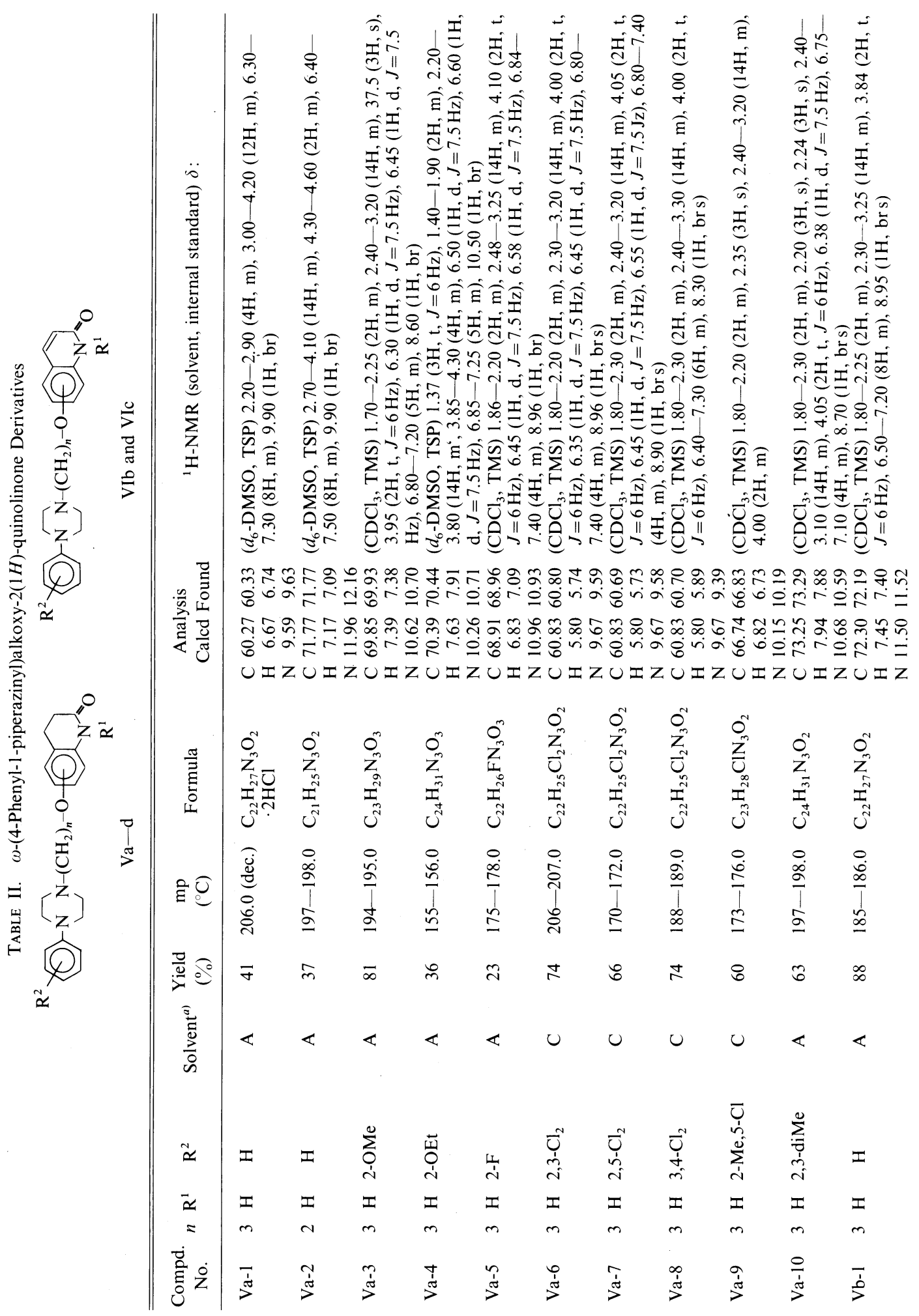




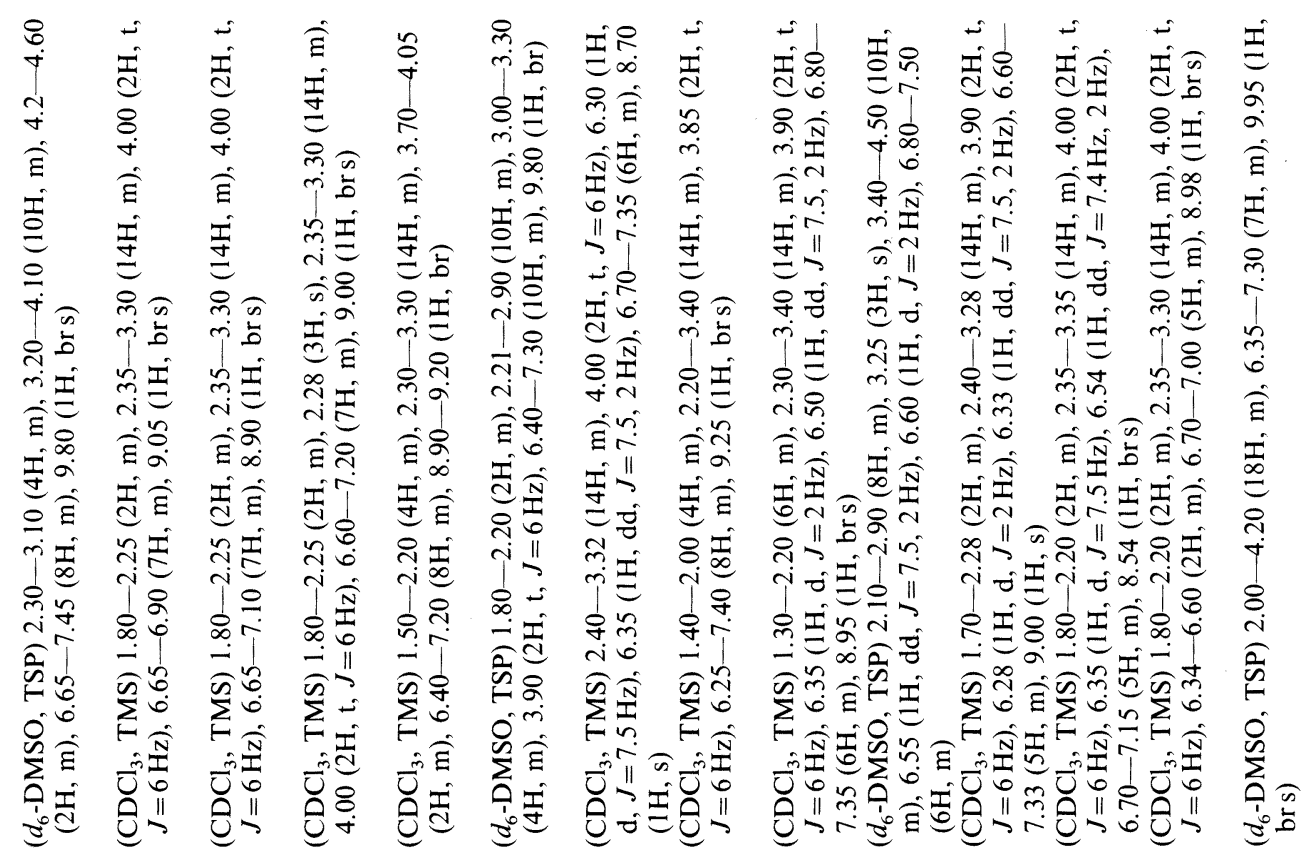

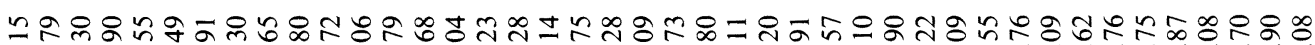

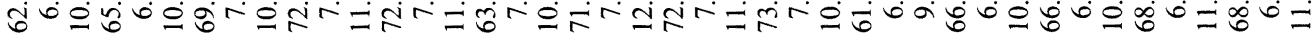

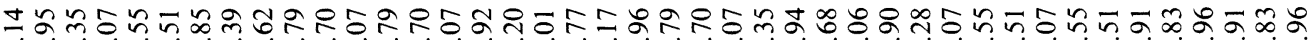

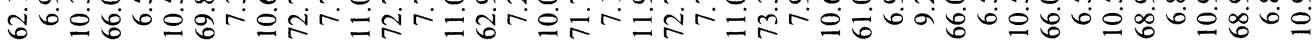
UIZUIZUIZUIZUIZUIZUIZUIZUIZUIZUIZUIZUIZUIZ

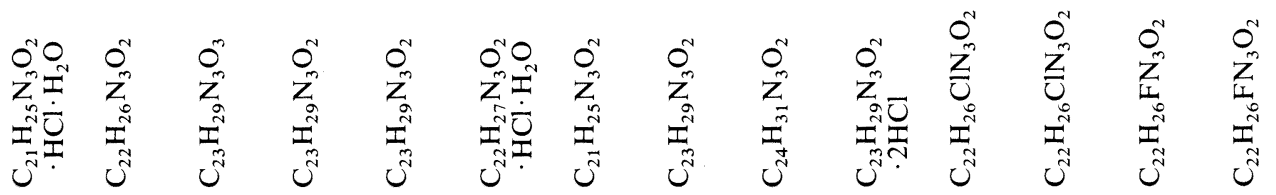

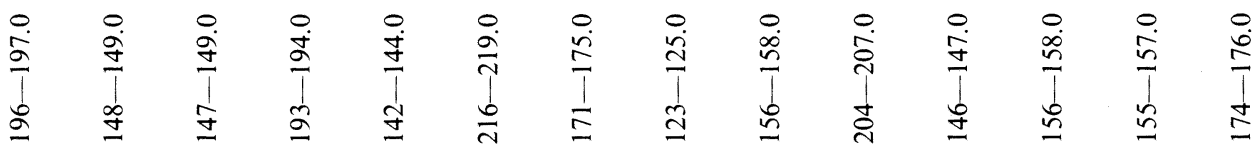

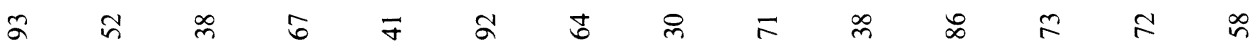

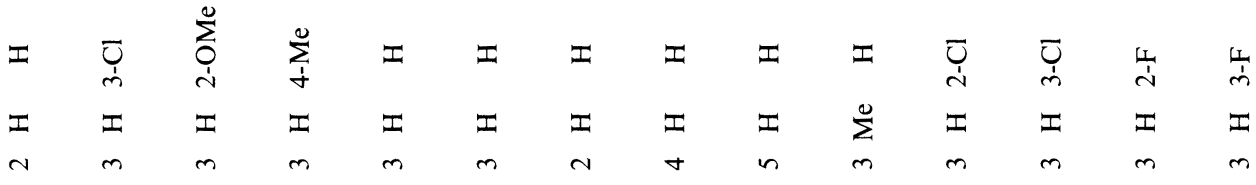

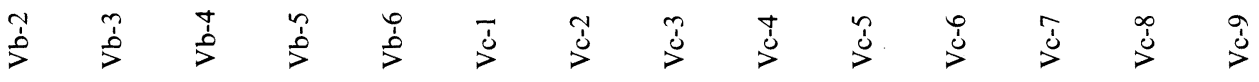




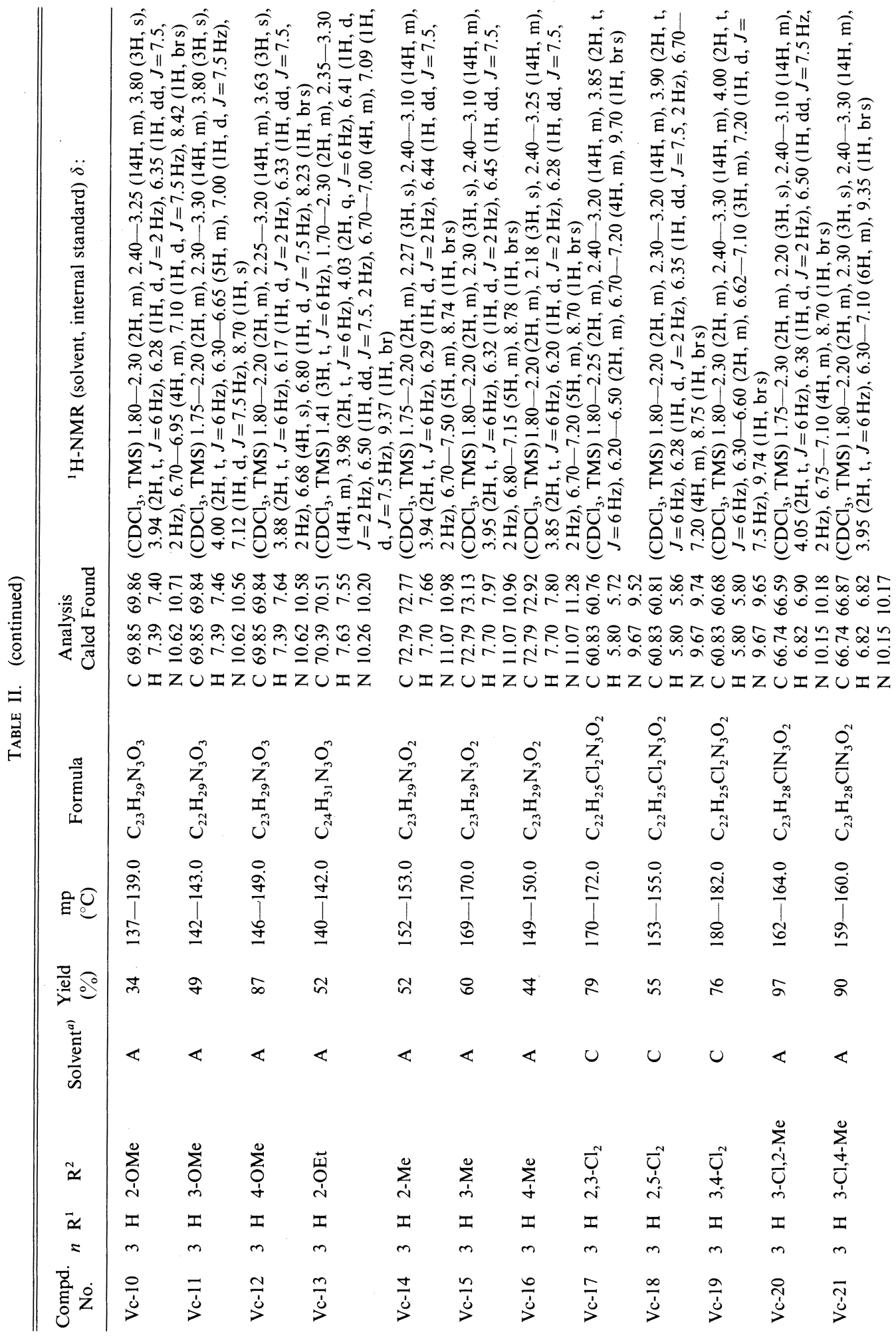




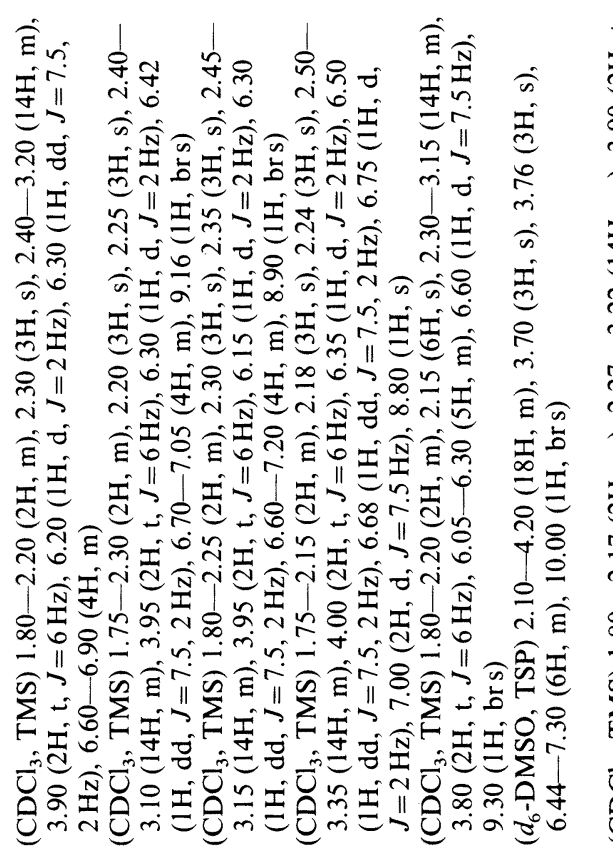

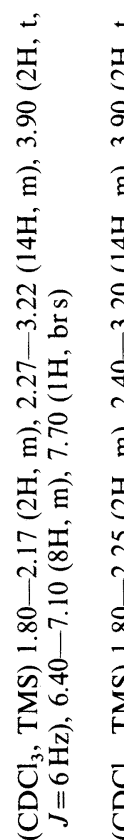

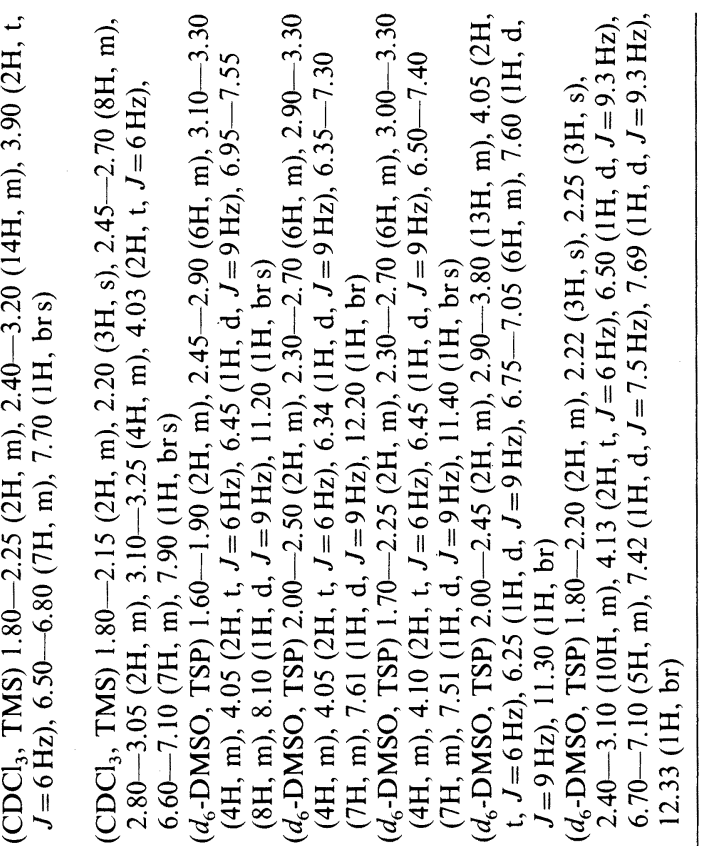

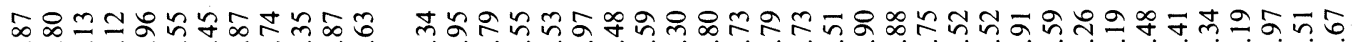

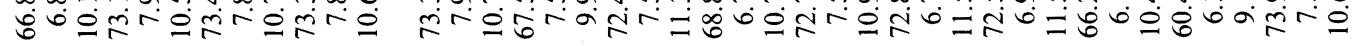

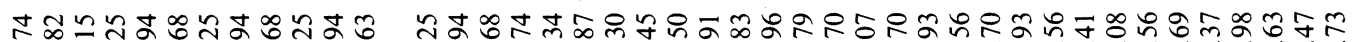

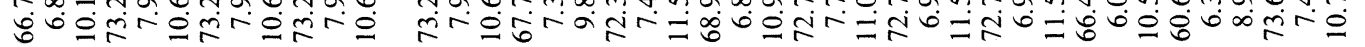

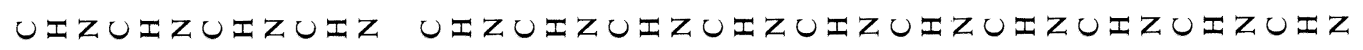

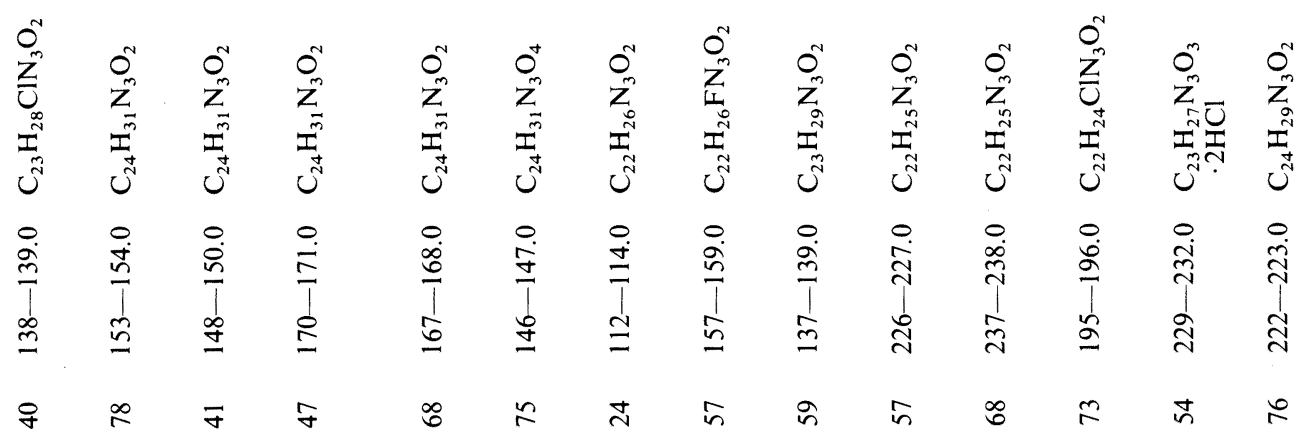

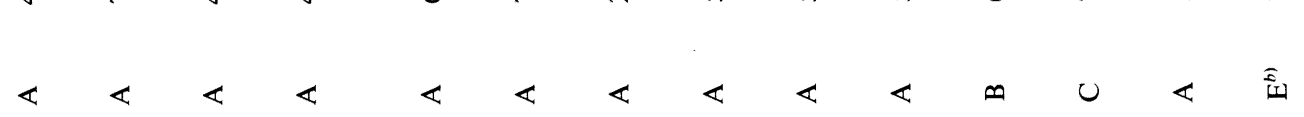

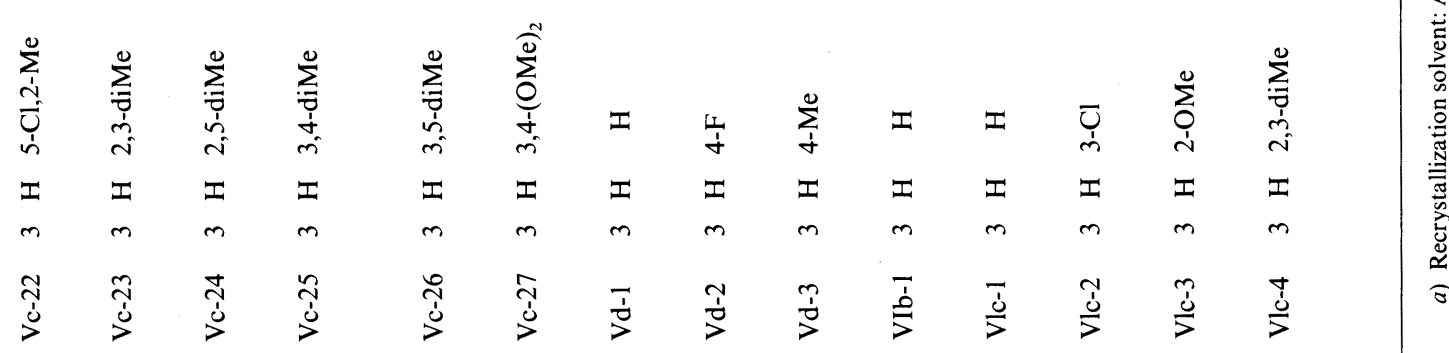


TABLE III. Pharmacology of 2(1H)-Quinolinone Derivatives

\begin{tabular}{|c|c|c|c|c|}
\hline & \multicolumn{2}{|c|}{$\begin{array}{l}\text { Anti-methamphetamine } \\
\text { activity }\left(\mathrm{ED}_{50} \mathrm{mg} / \mathrm{kg}\right)\end{array}$} & \multirow{2}{*}{$\begin{array}{c}\text { Anti-epinephrine } \\
\text { activity } \\
\left(\mathrm{ED}_{50} \mathrm{mg} / \mathrm{kg}\right)\end{array}$} & \multirow{2}{*}{$\begin{array}{c}\text { Induction of } \\
\text { catalepsy } \\
\left(\mathrm{ED}_{50} \mathrm{mg} / \mathrm{kg}\right)\end{array}$} \\
\hline & $\begin{array}{l}\text { Inhibition of } \\
\text { jumping behavior }\end{array}$ & $\begin{array}{l}\text { Inhibition of } \\
\text { group toxicity }\end{array}$ & & \\
\hline Va-1 & 2.10 & 9.10 & 2.00 & $>64$ \\
\hline $\mathrm{Vb}-1$ & 6.40 & nt & 4.80 & $>64$ \\
\hline Vc-1 & 9.30 & 4.20 & 47.6 & $>64$ \\
\hline $\mathrm{Vd}-1$ & $>16$ & $\mathrm{nt}$ & $>64$ & $n t$ \\
\hline Vc-2 & $>16$ & $\mathrm{nt}$ & 30.3 & $\mathrm{nt}$ \\
\hline Vc-3 & 9.50 & $\mathrm{nt}$ & 41.7 & $\mathrm{nt}$ \\
\hline $\mathrm{Vc}-4$ & $>16$ & $\mathrm{nt}$ & nt & nt \\
\hline Vc-5 & 10.7 & $\mathrm{nt}$ & $\mathrm{nt}$ & nt \\
\hline Va-3 & 1.60 & $\mathrm{nt}$ & 0.63 & 21.4 \\
\hline $\mathrm{Va}-4$ & 0.53 & 2.64 & 0.07 & 23.5 \\
\hline Va-5 & 0.46 & $\mathrm{nt}$ & 1.30 & 14.0 \\
\hline Vc-6 & 3.00 & 1.10 & 4.80 & 40.8 \\
\hline Vc-7 & 2.20 & 1.20 & 29.4 & 46.3 \\
\hline Vc-8 & 1.90 & 0.77 & 4.80 & 19.5 \\
\hline Vc-9 & 7.40 & 6.90 & 21.5 & $>64$ \\
\hline Vc-10 & 2.80 & 0.90 & 2.50 & 15.0 \\
\hline Vc-11 & 2.88 & 4.12 & 2.99 & $>64$ \\
\hline Vc-13 & 2.80 & $\mathrm{nt}$ & 0.71 & 26.3 \\
\hline Vc-14 & 0.70 & 5.22 & 0.85 & 18.3 \\
\hline $\mathrm{Vc}-15$ & 1.57 & 1.47 & 3.71 & $>64$ \\
\hline Vc-16 & 1.83 & 4.07 & 5.52 & $>64$ \\
\hline Vc-17 & 37.4 & $>16$ & $>64$ & $>64$ \\
\hline Vc-18 & 5.74 & $\mathrm{nt}$ & 40.0 & $\mathrm{nt}$ \\
\hline Vc-19 & 7.91 & nt & 12.0 & nt \\
\hline Vc-20 & 2.82 & $>64$ & $>64$ & $>64$ \\
\hline $\mathrm{Vc}-21$ & 2.82 & 46.4 & $>64$ & $\mathrm{nt}$ \\
\hline Vc-22 & 4.27 & $>64$ & nt & $\mathrm{nt}$ \\
\hline Vc-23 & 1.22 & 0.66 & 31.6 & 32.0 \\
\hline Vc-24 & 4.05 & $\mathrm{nt}$ & 7.90 & $\mathrm{nt}$ \\
\hline Vc-25 & 5.50 & $\mathrm{nt}$ & 6.20 & nt \\
\hline VIc-1 & 8.00 & 3.40 & 4.00 & 25.4 \\
\hline VIc-2 & 3.60 & 1.30 & 3.20 & $>64$ \\
\hline VIc-3 & 3.70 & $\mathrm{nt}$ & 0.79 & 40.3 \\
\hline VIc-4 & 2.74 & 1.84 & 56.6 & 23.0 \\
\hline Chloromazine & 7.60 & 4.90 & 10.6 & 10.7 \\
\hline Haloperidol & 1.80 & 0.44 & $>64$ & 0.97 \\
\hline
\end{tabular}

nt means not tested. All experiments in this table were carried out using mice.

summarized in Table III.

Typical neuroleptic drugs such as chlorpromazine and haloperidol are known to increase the level of the major metabolite of DA, 3,4-dihydroxyphenylacetic acid (DOPAC) in the rat brain, and this increase in the DOPAC level was suggested to be due to an increase in DA release resulted from blocking the DA receptor by a negative feedback mechanism. ${ }^{12)}$ The DA agonist apomorphine ${ }^{12)}$ or DA autoreceptor stimulant 3-(3-hydroxyphenyl)- $N-n$ propylpiperidene (3-PPP) ${ }^{13)}$ was reported to inhibit the haloperidol-induced increase in the DOPAC level in the rat brain. We examined several compounds which exhibited relatively high potency in the anti-jumping bahavior test for their effects on the haloperidol-induced increase in the DOPAC level in the rat brain region. The results are summarized in Table IV. 


\section{Structure-Activity Relationship}

First, anti-methamphetamine activity in the jumping behavior test of the positional isomers of the 3,4-dihydro-2-( $1 H)$-quinolinone series was investigated. The results (Table III) showed that the 5-isomer (Va-1) exhibited the highest potency when side chain substitution was maintained as the 3-(4-phenyl-1-piperazinyl)propoxy moiety, and the 6- and 7-isomers were less active (Vb-1 and $\mathrm{Vc}-1$ ), while the 8-isomer ( $\mathrm{Vd}-1)$ was inactive in this test.

Next, the $\alpha$-adrenoceptor blocking activity of these positional isomers was examined. It was found that the 5 -isomer was most potent, the 6-isomer was a little less active, and the 7isomer was much less active. The 8 -isomer did not show any activity in this test. Lack of $\alpha$ adrenoceptor blocking activity is considered advantageous for neuroleptic drugs because this activity is associated with undesirable autonomic side effects. Therefore, we selected the 7isomer, which exhibited anti-methamphetamine activity and only weak $\alpha$-adrenoceptor blocking activity. Further comparison of the activity of various substituents was made within the 7-isomer series.

The effects of the number of methylene groups $(n)$ in the side chain (4-phenyl-1piperazinyl)- $\left(\mathrm{CH}_{2}\right)_{n}$-O-moiety attached to the 7-position in the 3,4-dihydro-2(1 H)-quinolinone were examined. It was found that potency order of anti-methamphetamine activity was $n=3(\mathrm{Vc}-1) \geqq 4(\mathrm{Vc}-3) \gg 2(\mathrm{Vc}-2)$ and $5(\mathrm{Vc}-4)$.

The $\mathrm{N}^{1}$ substitution effect was examined and it was found that the nonsubstituted derivative (Vc-1) was more active than the $\mathrm{N}^{1}$-methyl derivative $(\mathrm{Vc}-5)$ in the jumping behavior test. Next, the effect of substitution on the phenyl group of 7-[3-(4-phenyl-1piperazinyl)propoxy-3,4-dihydro-2( $1 H)$-quinolinone was examined. In general, the monoor disubstituion on the phenyl group was found to enhance the potency of antimethamphetamine activity in the jumping behavior test. However, the introduction of dichloro substitution at the 2 and 3 positions on the phenyl ring in the phenylpiperazinyl moiety significantly reduced the activity ( $\mathrm{Vc}-17)$. In this test, several compounds were found to be more potent than haloperidol, and the order of potency of the substituents of these compounds is $2-\mathrm{CH}_{3}(\mathrm{Vc}-14)>2,3-\left(\mathrm{CH}_{3}\right)_{2} \quad(\mathrm{Vc}-23)>2-\mathrm{F}(\mathrm{Vc}-8)$. With respect to the $\alpha-$ adrenoceptor blocking activity, it was found that the introduction of substituents in the phenyl group enhanced the potency. Generally, the potency of the monosubstituted derivatives was much higher than that of disubstituted derivatives.

As regards the nucleus, we found that the 2-(1H)-quinolinone derivatives were a little less active in the jumping behavior test than the 3,4-dihydro-2(1H)-quinolinone derivatives (Vc-7 > VIc-3, Vc-23 > VIc-4 and Vc-8 > VIc-2).

Typical neuroleptic drugs inhibit the lethal effects of methamphetamine on mice. ${ }^{10)}$ The compounds examined were active in this test. Several compounds exhibited much higher potency than that of chlorpromazine.

Typical neuroleptic drugs also exhibit cataleptogenic activity. It was found that several of the compounds examined were active in the induction of catalepsy in mice. However, no clearcut correlation between the potency of cataleptogenic activity and the anti-methamphetamine activities could be found. The potency of the compounds examined was much less than that of chlorpromazine or haloperidol.

It was reported that short-term change in the brain level of DOPAC may be a useful index of alteration in the functional activity of central dopaminergic neurons, ${ }^{12)}$ and chlorpromazine and haloperidol increased the DOPAC level in the rat brain while the DA agonist apomorphine or DA autoreceptor stimulant 3-PPP decreased the DOPAC level. Several compounds were examined for effects on the haloperidol-induced increase in the DOPAC level in the rat brain region. As shown in Table IV, compounds Vc-7, Vc-15 and VIc4 were found to block the increase in the DOPAC level induced by haloperidol in the frontal cortex (FC), stratum (ST) and limbic forebrain (LF) region. Compound Vc-6 did not affect 
TABLE IV. Effects of $2(1 H)$-Quinolinone Derivatives on the Increase in Concentration of 3,4-Dihydroxphenylacetic acid (DOPAC) Induced by Haloperidol in Discrete Brain Region of the Rat

\begin{tabular}{ccccc}
\hline \hline \multirow{2}{*}{ Compound } & $\begin{array}{c}\text { Dose } \\
\text { (mg/kg p.o. })\end{array}$ & \multicolumn{3}{c}{ Concentration of DOPAC (\% of control) } \\
& FC & LF & ST \\
\hline Va-4 & 10 & 137 & 146 & 93 \\
Vc-6 & 10 & 108 & 99 & 73 \\
Vc-7 & 10 & 52 & 51 & 36 \\
Vc-14 & 30 & 152 & 127 & 118 \\
Vc-15 & 30 & 50 & 76 & 36 \\
Vc-23 & 30 & 163 & 132 & 127 \\
VIc-4 & 30 & 73 & 72 & 65 \\
\hline
\end{tabular}

Each value represents the percentage concentration upon treatment with the compound and haloperidol with respect to that upon treatment with haloperidol alone (control).

the increase in the DOPAC level, but compounds $\mathrm{Va}-4, \mathrm{Vc}-14$ and $\mathrm{Vc}-23$ enhanced the increase in the DOPAC level induced by haloperidol at the FC and the ST region. Compounds Vc-7, Vc-15 and VIc-4 blocked the methamphetamine toxicity in mice, in contrast with apomorphine. ${ }^{11)}$ These results suggest that these compounds possess DA autoreceptor agonistic activity.

Among these three compounds, Vc-7 (OPC-4139) and VIc-4 (OPC-4392) were selected for further preclinical investigations because the compounds exhibited relatively high potency in the anti-methamphetamine activity and reduced side effects such as $\alpha$-adrenoceptor blocking and cataleptogenic activities. In the preclinical study, the compounds were confirmed to be DA autoreceptor agonists, ${ }^{14-16)}$ and VIc-4 (OPC-4392) was selected for clinical trial because of its higher safety margin in the toxicological study.

\section{Experimental}

All melting points are uncorrected. Nuclear magnetic resonance (NMR) spectra were recorded on a Varian EM390 NMR spectrometer using tetramethylsilane (TMS) or 3-(trimethylsilyl)propionic acid- $d_{5}$ (TSP) as an internal standard.

Preparation of $\omega$-Haloalkoxy-3,4-dihydro-2(1H)-quinolinone Derivatives (IIIa-1 - IIId). 7-(3-Chloropropoxy)-3,4-

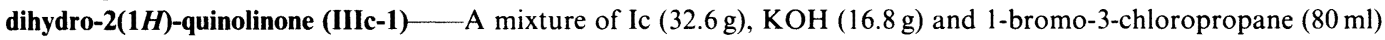
in $500 \mathrm{ml}$ of iso-PrOH was refluxed for $4 \mathrm{~h}$, and the hot reaction mixture was filtered. The filtrate was cooled, and the precipitated crystals were collected by filtration. Recrystallization from EtOH gave IIIc- $1(24.4 \mathrm{~g}, 51 \%)$ as colorless needles, mp $118-119^{\circ} \mathrm{C}$.

Compounds IIIa-1, IIIa-2, IIIc-2-IIIc-4 and IIId were obtained in the same manner as described for IIIc-1. The yields, melting points, elementary analysis data, and NMR data are given in Table $\mathrm{I}$.

Preparation of 6 or 7-(3-Chloropropoxy)-2(1 H)-quinolinone (IVb or IVc). 7-(3-Chloropropoxy)-2(1H)-quinolinone (IVc) - 1-Bromo-3-chloropropane $(20 \mathrm{ml})$ was added to a boiling solution of IIc $(8.4 \mathrm{~g})$ and $\mathrm{KOH}(4.5 \mathrm{~g})$ in $150 \mathrm{ml}$ of iso- $\mathrm{PrOH}$, and the mixture was refluxed for $20 \mathrm{~h}$. The hot reaction mixture was diluted with $150 \mathrm{ml}$ of EtOH, and the precipitated materials were filtered off. The filtrate was cooled and the precipitated crystals were collected by filtration. Recrystallization from EtOH gave IVc $(5.0 \mathrm{~g}, 40 \%)$ as colorless needles, $\mathrm{mp} 130-133^{\circ} \mathrm{C}$.

Similarly, compound IVb was obtained from IIb. The elementary analysis data, melting points, yield and NMR data are given in Table II.

Preparation of $\omega$-(4-Phenyl-1-piperazinyl)alkoxy-3,4-dihydro-2(1H)-quinolinone Derivatives (Va-1-Vd). 7-[3-(4Phenyl-1-piperazinyl)propoxy]-3,4,-dihydro-2(1 H)-quinolinone Hydrochloride (Vc-1)—A suspension of IIIc-1 (1.8 g) and $\mathrm{NaI}(1.8 \mathrm{~g})$ in $50 \mathrm{ml}$ of $\mathrm{CH}_{3} \mathrm{CN}$ was refluxed for $4 \mathrm{~h}$, then 4-phenylpiperazine $(3.2 \mathrm{~g})$ was added to the suspension, and the mixture was refluxed a further $10 \mathrm{~h}$. The residue was extracted with $200 \mathrm{ml}$ of $\mathrm{CHCl}_{3}$, and the extracts were washed with water, dried over anhydrous $\mathrm{MgSO}_{4}$, and again evaporated to dryness. The residue was dissolved in $200 \mathrm{ml}$ of $\mathrm{EtOH}$, and acidified with $\mathrm{HCl}$ gas-saturated EtOH solution, then evaporated under reduced pressure. Recrystallization from EtOH gave Vc-1 $(3.85 \mathrm{~g}, 92 \%)$ as a white powder, mp $216-219^{\circ} \mathrm{C}$. 
Compounds Va-1 and Vb-2 were obtained by the same method as described for Vc-1. The NMR data, elementary analysis data, melting points and yields are given in Table II.

7-\{3-[4-(2-Methylphenyl)-l-piperazinyl]propoxy\}-3,4-dihydro-2(1H)-quinolinone (Vc-14)—A suspension of IIIc-1 (2.5 g) and $\mathrm{NaI}(1.8 \mathrm{~g})$ in $50 \mathrm{ml}$ of $\mathrm{CH}_{3} \mathrm{CN}$ was refluxed for $4 \mathrm{~h}$, and then 4-(2-methyl-phenyl)piperazine (3.52 $\mathrm{g}$ ) was added to the mixture. After being refluxed for $10 \mathrm{~h}$, the reaction mixture was evaporated to dryness under reduced pressure, and the residue was extracted with $200 \mathrm{ml}$ of $\mathrm{CHCl}_{3}$. The extracts were washed with water, dried over anhydrous $\mathrm{MgSO}_{4}$, and evaporated to dryness. Recrystallization of the residue from EtOH gave $\mathrm{Vc}-14(1.97 \mathrm{~g}$, $52 \%$ ) as colorless needles mp $152-153{ }^{\circ} \mathrm{C}$.

Compounds Va-2-Va-10, Vb-1, Vb-3, Vc-2-Vc-4, Vc-7-Vc-27 and Vd-1-Vd-3 were obtained by the same procedure as described for $\mathrm{Vc}-14$. The NMR data, elementary analysis data, melting points and yields are given in Table II.

Preparation of $\omega$-(4-Phenyl-1-piperazinyl)alkoxy-2(1H)-quinolinone Derivatives (VIb-1, and VIc-1 VIc-4). 7-[3-(4Phenyl-1-piperazinyl)propoxy]-2(1H)-quinolinone (VIc-1)-A suspension of IVc $(1.3 \mathrm{~g})$ and $\mathrm{NaI}(1.1 \mathrm{~g})$ in $50 \mathrm{ml}$ of $\mathrm{CH}_{3} \mathrm{CN}$ was refluxed for $5 \mathrm{~h}$, then 4-phenylpiperazine $(2.5 \mathrm{~g})$ was added to the suspension. After being refluxed for $5 \mathrm{~h}$, the reaction mixture was evaporated under reduced pressure. The residue was extracted with $200 \mathrm{ml}$ of $\mathrm{CHCl}_{3}$, and the extracts were washed with water, dried over anhydrous $\mathrm{MgSO}_{4}$, and evaporated to dryness under reduced pressure. Recrystallization of the residue from EtOH gave VIc-1 $\left(1.27 \mathrm{~g}, 68 \%\right.$ ) as pale yellow needles, mp $237-238^{\circ} \mathrm{C}$.

Compounds VIb-1 and VIc-2 were obtained in the same manner as described for VIc-1, and the yields, melting points, elementary analysis data and NMR data are listed in Table II.

7-\{3-[4-(2-Methoxyphenyl)-1-piperazinyl]propoxy\}-2(1 H)-quinolinone Dihydrochloride (VIc-3) _ A suspension of IVc $(2.37 \mathrm{~g})$ and $\mathrm{NaI}(2.2 \mathrm{~g})$ in $100 \mathrm{ml}$ of $\mathrm{CH}_{3} \mathrm{CN}$ was refluxed for $5 \mathrm{~h}$, and cooled to room temperature. To this suspension was added 4-(2-methoxyphenyl)piperazine $(3.86 \mathrm{~g})$, and the mixture was refluxed for $22 \mathrm{~h}$. The reaction mixture was evaporated under reduced pressure, and the residue was extracted with $200 \mathrm{ml} \mathrm{of} \mathrm{CHCl}_{3}$. The extracts were washed with water, dried over anhydrous $\mathrm{MgSO}_{4}$, and again evaporated to dryness under reduced pressure. The residue was dissolved in $100 \mathrm{ml}$ of $\mathrm{EtOH}$, and acidified with $\mathrm{HCl}$ gas-saturated EtOH solution, and evaporated to dryness. Recrystallization of the residue from EtOH gave VIc-3 $(2.51 \mathrm{~g}, 54 \%)$ as a white powder, $\mathrm{mp} 229-232^{\circ} \mathrm{C}$.

7-\{3-[4-(2,3-Dimethylphenyl)-1-piperazinyl]propoxy $\}-2(1 \mathrm{H})$-quinolinone (VIc-4)-A suspension of IVc $(500 \mathrm{~g})$ and $\mathrm{NaI}(540 \mathrm{~g})$ in 51 of $\mathrm{CH}_{3} \mathrm{CN}$ was refluxed for $4 \mathrm{~h}$, then triethylamine $(500 \mathrm{ml})$ and 4 - $(2,3$-dimethylphenyl)piperazine $(400 \mathrm{~g})$ were added. After being refluxed for $4 \mathrm{~h}$, the reaction mixture was poured into 101 of $10 \% \mathrm{NaHCO}_{3}$ solution with vigorous stirring, and extracted with 121 of $\mathrm{CHCl}_{3}-\mathrm{MeOH}(10: 1)$. The extracts were washed with water, and evaporated under reduced pressure, and the oily residue was crystallized with the addition of 11 of iso-propyl ether. The crude crystals were collected by filtration and dissolved in $120 \mathrm{ml}$ of $\mathrm{CHCl}_{3}$. This solution was acidified with concentrated $\mathrm{HCl}$, and evaporated under reduced pressure. The residue was suspended in 11 of acetone and stirred for $1 \mathrm{~h}$, and then filtered off, washed with acetone, and dried. After being recrystallized from an aqueous $\mathrm{MeOH}$, VIc-4 hydrochloride was dissolved in 101 of $80 \%$ EtOH. The solution was poured into $0.25 \mathrm{~N} \mathrm{NaOH}$ solution (251) with vigorous stirring, and the precipitated crystals were collected by filtration, washed with water and dried. Thus, VIc- 4 was obtained as amorphous crystals $(230 \mathrm{~g}, 76 \%), \mathrm{mp} 222.0-223^{\circ} \mathrm{C}$.

Preparation of 1-Methyl-7-[3-(4-phenyl-1-piperazinyl)propoxy]-3,4-dihydro-2-(1 H)-quinolinone (Vc-5)- $-\mathrm{NaH}$ $60 \%,(0.6 \mathrm{~g})$ was added to a solution of $\mathrm{Vc}-1(3.65 \mathrm{~g})$ in $100 \mathrm{ml}$ of dimethylformamide (DMF) with stirring at room temperature, and the suspension was stirred for $30 \mathrm{~min}$. MeI $(1.40 \mathrm{~g})$ was then added, and the mixture was stirred for $2 \mathrm{~h}$. It poured into $300 \mathrm{ml}$ of water, and extracted with $200 \mathrm{ml}$ of AcOEt. The extracts were washed with water, dried over anhydrous $\mathrm{MgSO}_{4}$ and evaporated under reduced pressure. The residue was dissolved in $100 \mathrm{ml}$ of EtOH, acidified with concentrated $\mathrm{HCl}$, and evaporated to dryness under reduced pressure. Recrystallization of the residue from EtOH gave $\mathrm{Vc}-5(1.71 \mathrm{~g}, 38 \%)$ as a white powder, $\mathrm{mp} 204-207^{\circ} \mathrm{C}$.

Biological Methods and Materials

Animals - Male ICR mice (18.3 g) purchased from Clea Japan Inc. were fasted overnight $(18-20 \mathrm{~h})$ and used for experiments.

Chemicals_- L-DOPA was obtained from Nakarai Chemical Co., Ltd. Methamphetamine $\mathrm{HCl}$ and haloperidol were purchased from Dai-Nippon Pharmaceutical Co., Ltd. Chloropromazine $\mathrm{HCl}$ and epinephrine were obtained from Yoshitomi Pharmaceutical Co., Ltd. and Daiichi Pharmaceutical Co., Ltd. respectively.

Anti-jumping Behavior Test — The experiment was performed according to the method of Lal et al. ${ }^{10)}$ The test compounds and reference drugs were orally administered to groups of 10 mice. Methamphetamine $\mathrm{HCl}$ was injected $(4 \mathrm{mg} / \mathrm{kg}$ i.p.) at $45 \mathrm{~min}$ after administration of the test compounds followed by L-DOPA injection of $400 \mathrm{mg} / \mathrm{kg}$ i.p. The mice were placed in 21 beakers, and jumping was counted for $50 \mathrm{~min}$ starting $10 \mathrm{~min}$ after the L-DOPA injection. When the jumping count was less than 10 times during the 50 min observation period, the animal was judged to be a positive responder, and the $\mathrm{ED}_{50}$ value was calculated using Lichfield-Wilcoxon's method. ${ }^{17)}$

Anti-epinephrine Test - The test compounds and reference drugs were orally administered to groups of 10 mice. Epinephrine was injected at $40 \mathrm{mg} / \mathrm{kg}$ i.p. $60 \mathrm{~min}$ after administration of the test compounds or reference drugs. The mice were immediately placed in animal cages $(18 \times 24 \times 12 \mathrm{~cm})$ in groups of 10 , and the $24 \mathrm{~h}$ survival rate was obtained in a soundproof room. Survivals were considered to be positive responders to the anti-epinephrine test, 
and the $\mathrm{ED}_{50}$ value was calculated using the Lichfield--Wilcoxon method.

Anti-methamphetamine Group Toxicity Test_-The experiment was performed according to the method of Lagerspetz and Lagerspetz. ${ }^{18)}$ The test compounds and reference drugs were administered to groups of 10 mice. Methamphetamine $\mathrm{HCl}$ was injected at $20 \mathrm{mg} / \mathrm{kg}$ i.p. $60 \mathrm{~min}$ after administration of the test compounds and reference drugs. The mice were immediately placed in animal cages $(16 \times 12 \times 12 \mathrm{~cm})$ in groups of 10 , and the $24 \mathrm{~h}$ survival rate was obtained in a sound-proof room at $26-28^{\circ} \mathrm{C}$. Survivors were considered to be positive responders to this test, and the $\mathrm{ED}_{50}$ value was calculated using the Lichfield-Wilcoxon method.

Cataleptogenic Test_- The test compounds and reference drugs were administered to groups of 10 mice, and induction of catalepsy was observed at $0,1,2,4,6$ and $8 \mathrm{~h}$ after administration. The animals were put in an unnatural posture with their forelimbs on a vertical $6.5 \times 10 \times 0.2 \mathrm{~cm}$ plate. When this posture was maintained for over 30 seconds, the animal was judged to have catalepsy. The observation was repeated three times after each administration. Animals that remained in the posture for less than $30 \mathrm{sec}$ in all three test were not considered to be cataleptic. The $\mathrm{ED}_{50}$ value was calculated by the Lichfield-Wilcoxon method.

Assay of DOPAC Level in the Rat Brain - Male Wistar rats weighing 170-200 g (purchased from Clea Japan Inc.) were fasted overnight $(16-18 \mathrm{~h})$ and used in the experiment. The test compounds were administered to groups of 3-5 rats at a dose indicated in Table IV before haloperidol treatment $(0.1 \mathrm{mg} / \mathrm{kg}$ i.p. $)$. The rat head was exposed to microwaves in a microwave oven (Toshiba TMW-6402 Type, $3.5 \mathrm{~kW}, 1.5 \mathrm{~s}$ ) $1 \mathrm{~h}$ after haloperidol treatment and immediately cooled in ice. The whole brain was removed and separated into the frontal cortex (FC), limbic forebrain (LF) and striatum (ST) according to the methods of Glowiniski and Iversen ${ }^{19)}$ and Blumberg et al. ${ }^{20)}$ The tissue weight were determined, and the tissue was homogenized with $1 \mathrm{~N} \mathrm{HCOOH}$ containing dihydroxybenzoic acid as the internal standard. The homogenate was centrifuged for $20 \mathrm{~min}$ at $4{ }^{\circ} \mathrm{C}(14000 \mathrm{rpm})$, and $1 \mathrm{ml}$ of the supernatant was extracted with $5 \mathrm{ml}$ of AcOEt. The extract was evaporated to dryness, and used for the DOPAC assay. The DOPAC assay was carried out according to the method reported by Yasuda et al. ${ }^{21)}$ The results are summarized in Table IV.

\section{References}

1) P. A. J. Janssen, C. J. E. Niemergeers and K. H. L. Schellenkens, Arzneim-Forsch (Drug Research), 15, 104 (1965).

2) S. H. Snyder, S. P. Banerjee, H. I. Yamamura and D. Greenberg, Science 184, 1243 (1974).

3) H. M. Van Praag, "Psychotropic Drugs," ed. by Von Gorucum, Assen, Netherland, 1978.

4) G. M. Simpson, E. H. Pi and J. J. Sramek, Jr., Drugs, 21, 138 (1981); idem, ibid., 23, 381 (1982).

5) K. Nakagawa, N. Murakami, S. Yoshizaki, M. Tominaga, H. Mori, Y. Yabuuchi and S. Shintani, J. Med. Chem., 17, 529 (1974).

6) S. Yoshizaki, K. Tanimura, S. Tamada, Y. Yabuuchi and K. Nakagawa, J. Med. Chem., 19, 1138 (1976).

7) T. Nishi, K. Yamamoto, T. Shimizu, K. Kanbe, Y. Kimura and K. Nakagawa, Chem. Pharm. Bull., 31, 798 (1983).

8) K. Banno, T. Fujioka, Y. Oshiro and K. Nakagawa, Japan. Patent (Laid-Open) No. 127371 (1980) [Chem. Abstr., 94, 121352r (1980)].

9) Unpublished Data.

10) H. Lal, F. C. Colpaert and P. Laduron, Eur. J. Pharmacol., 30, 113 (1975).

11) T. Homma, Nippon Yakurigaku Zasshi, 74, 27 (1978).

12) R. H. Roth, L. C. Murrin and J. R. Walters, Eur. J. Pharmacol., 36, 163 (1976).

13) S. Hjorth, A. Carlsson, H. Wikstrom, P. Lindberg, D. Sanchez, U. Kacksell, L. E. Arridsson, U. Svensson and J. L. G. Nilsson, Life Sci., 28, 1225 (1981).

14) K. Kikuchi, Y. Yasuda, N. Suzuki, M. Tsutsui, T. Hiyama and Y. Yabuuchi, Abstracts of Papers, 8th International Congress of Pharmacology, Tokyo, Japan, July 1981, p. 380.

15) Y. Yasuda, T. Kikuchi, K. Yamada, S. Suzuki, M. Tsutsui, T. Hiyama and Y. Yabuuchi, Jpn. J. Pharmacol., 40, Supplementum 83p (1986).

16) S. Suzuki, M. Tsutsui, T. Kikuchi, Y. Yasuda, K. Yamada, T. Hiyama and Y. Yabuuchi, Jpn. J. Pharmacol., 40, Supplementum 129p (1986).

17) J. T. Litchfield and F. Wilcoxon, J. Pharmacol. Exp. Ther., 95, 99 (1949).

18) K. Y. H. Lagerspetz and K. M. J. Lagerspetz, J. Pharm. Pharmacol., 23, 542 (1971).

19) J. Glowiniski and L. L. Iversen, J. Neurochem., 13, 655 (1966).

20) J. B. Blumberg, J. Vetulani, R. J. Stawarz and F. Sulser, Eur. J. Pharmacol., 37, 357 (1976).

21) Y. Yasuda, Y. Shioya, T. Nakai, S. Shintani and T. Hiyama, Nippon Yakurigaku Zasshi, 79, 173 (1982). 